\title{
Migratory Localization of Cyclin D2-Cdk4 Complex Suggests a Spatial Regulation of the G1-S Transition
}

\author{
Zizhang Wang ${ }^{1,2^{*}}$, Yongli Xie ${ }^{2}$, Lixia Zhang ${ }^{2}$, Haiwen Zhang ${ }^{2}$, Xiaojing An ${ }^{1}$, Tai Wang ${ }^{1}$, and \\ Anming Meng ${ }^{2}$ \\ ${ }^{1}$ Research Center for Molecular and Developmental Biology, Institute of Botany, Chinese Academy of \\ Sciences, Beijing 100093, China and ${ }^{2}$ Department of Biological Sciences and Biotechnology, Tsinghua \\ University, Beijing 100084, China
}

\begin{abstract}
The association of the cyclin D-Cdk (DC) complex with retinoblastoma protein (pRb) is required for the G1-S transition of the cell cycle. Cyclin synthesis, nuclear localization and degradation are control mechanisms for the transition, but regulation of the DC complex nuclear import also contributes to the transition. Analysis of the timing of the G1-S transition in mammalian cell lines revealed acceleration with overexpression of cyclin D2 and Cdk4. Immunolocalization assays revealed that cyclin D2 and Cdk4 formed a complex in the cytoplasm and approached the nucleus. They accumulated on the cytosolic surfaces of the nuclear pores and then were arrested at the nuclear membrane before the nucleus reached a critical size. Finally, the complex was released into the nucleus and colocalized with $\mathrm{pRb}$ there, which led to $\mathrm{pRb}$ phosphorylation and DNA synthesis. The translocalization depended on the G1-S transition. In contrast, a truncated cyclin D2 that was not able to fully associate with Cdk4 lost the ability for release into the nucleus. This pattern of translocalization suggests a spatial separation of the cyclin D-Cdk complex from pRb and DNA in the nucleus to regulate the G1-S transition.
\end{abstract}

Key words: cyclin D2-Cdk4 complex/cytoplasmic-nuclear translocalization/nuclear pore/pRb/G1-S transition

\section{Introduction}

D-type cyclins (cyclin Ds), in sensing growth factors, serve as the initial controller of the cell cycle (Sherr and Roberts, 1999), but a restriction (R) point acts as an irreversible commitment to the cycle at the G1-S transition (Zetterberg and Larsson 1995; Alberts et al., 2002). Cyclin Ds assemble with cyclin-dependent kinases (Cdks) to form cyclin D-Cdk complexes (DC complexes), whose substrate is the retinoblastoma protein (pRb) (Kato et al., 1993). DC complexes phosphorylate $\mathrm{pRb}$ to activate the transcription of E2Fresponsive genes, which are required for the G1-S transition (Ikeda et al., 1996; Moberg et al., 1996).

The formation and activation of a DC complex occurs sequentially. First, genes encoding cyclin Ds are induced in

\footnotetext{
*To whom correspondence should be addressed: Zizhang Wang, Research Center for Molecular and Developmental Biology, Institute of Botany, Chinese Academy of Sciences, Beijing 100093, China.

Tel: +86-10-62836204, Fax: +86-10-62594170

E-mail: zizhangw@mail.tsinghua.edu.cn

Abbreviations: DC complex, D-type cyclin-Cdk complex; D2C4 complex, cyclin D2-Cdk4 complex; pRb, retinoblastoma protein; NPC, nuclear pore complex; NE, nuclear envelope.
}

response to mitogenic signals; cyclin Ds associate with Cdks as cells progress through the G1 phase (Sherr, 1993). DC complexes enter the nucleus to phosphorylate $\mathrm{pRb}$ substrates (Sherr and Roberts, 1999; Szekely et al., 1991). Furthermore, formation of the DC complex and phosphorylation of the Cdks are independently regulated (Kato et al., 1994).

Cyclin Ds show a very low cytoplasmic distribution in a quiescent cell and begin to accumulate after the addition of serum; the accumulation is maintained and peaks before the S phase (Baldin et al., 1993; Diehl et al., 1998). In the nucleus, the DC complex binds to one specific site on the $\mathrm{pRb}$, phosphorylates the $\mathrm{pRb}$ and liberates the cyclin E-Cdk2 complex from Cip/Kip inhibition; in turn, the liberated cyclin E-Cdk2 complex reinforces phosphorylation of the $\mathrm{pRb}$ on additional sites. By this process, cells complete their entry into the $\mathrm{S}$ phase (Sherr and Roberts, 1999; Lundberg et al., 1998; Perez-Roger et al., 1999).

The transmembrane control of these regulators is important in cell division regulation. The nuclear envelope gives the regulators the opportunity to access nuclear DNA (Rout et al., 2003). Proteins targeting the nucleus first interact in the cytoplasm with importins and dock at multiple sites 
through the nuclear pore complex (Moore et al., 1992; Panté and Aebi, 1996), and a small GTPase, Ran, provides directionality to nucleocytoplasmic transport during interphase (Weis, 2003). The nuclear import of the DC complex is through direct interaction of the cyclin components with importins (Moore et al., 1999). However, whether the nuclear membrane participates in cell cycle regulation remains unknown.

Overexpression of cyclin D1 accelerates cell entry into the S phase (Resnitzky et al., 1994), but coexpression of cyclin D2 and Cdk4 results in a faster onset of DNA synthesis than expression of cyclin D1 or D2 alone (Quelle et al., 1993). To further understand the G1-S transition, we coexpressed cyclin D2 and Cdk4 (D2C4 complex) in mammalian cells and analyzed the localization patterns of this DC complex and its mutant by indirect immunofluorescence. After being arrested on the nuclear membrane, the D2C4 complex translocated from the cytoplasm to the nucleus, which allowed for transition from the G1 to S phase.

\section{Materials and Methods}

\section{Amplification of genes and production of a cyclin D2 mutant}

The entire open reading frames of cyclin D2, Cdk4, Nup 153, Rb and lamin B genes were amplified from cDNA of HEK293T cells by PCR with appropriate primers. A truncated cyclin D2 fragment was produced with forward primer (5'-AAGAATTCATGCGCAGAATGGTGGCCAC-3') and reverse primer (5'-AAGTCGACTCACAGGTCGATATCCCGCA-3') containing the cyclin-box folds $(\mathrm{CBFs})$ and its downstream region without the upstream region, which harbored the $\mathrm{L} \times \mathrm{C} \times \mathrm{E}$ motif and the $\mathrm{N}$-terminal helix. These genes were cloned and the sequences were confirmed.

\section{Interaction of cyclin D2 and Cdk4 on yeast two-hybrid assay}

Briefly, the cyclin D2 gene and the truncated cyclin D2 fragment were inserted in-frame into the $E c o \mathrm{R} I / S a l$ I cloning site of plasmid pBD-GAL4 to create fusion proteins with the GAL4 DNA-binding domain, and the $\mathrm{Cdk} 4$ gene was inserted in-frame into plasmid pAD-GAL4 to fuse with the coding region for the GAL4 transcriptional activation domain. The full-length or truncated cyclin D2 gene constructs were cotransformed with the $\mathrm{Cdk} 4$ gene construct into the YRG-2 yeast strain by a yeast two-hybrid system (Stratagene, La Jolla, CA). The cotransformed yeast cells were plated on SD-selective media without Leu and Trp or without Leu, Trp and His to test the expression or interaction of target proteins in the host cells. Filter lift assay was performed for cotransformants that could grow on the medium without His, to confirm the activity of $\beta$-galactosidase.

\section{Cell culture, expression plasmid construction and cell transfection}

HEK293T, Hela and NIH-3T3 cells were kindly provided by Professor Yeguang Chen in our department. Cells were grown in DMEM plus $10 \%$ fetal bovine serum (FBS). Cyclin D2 and its truncated mutant genes were subcloned in-frame into the mammalian expression vector pCMV-Myc, whereas the Cdk4 gene Nterminally tagged with flag epitope and hemagglutinin (HA)tagged Rb, Nup153 and lamin B genes, mediated by PCR, were subcloned into the pCMV5 vector to create expression plasmids. The sequences of these tags were as follows: myc, 5' ACC ATG GAA CAG AAG CTA ATC AGC GAA GAG GAT CTA 3'; flag, 5' ACC ATG GAC TAC AAG GAC GAC GAT GAC AAG 3'; and HA, 5' ACC ATG TAT CCG TAT GAT GTT CCT GAT TAT GCT AGC CTC 3'. Four tandem copies of myc or flag were produced by DNA synthesis and were subcloned into corresponding empty vectors as controls. Transfection of plasmids into cells involved the calcium phosphate method as described previously (Chen et al., 1998; Zhang et al., 2004).

\section{Creation of stable cell lines with regulated expression of cyclin D2 and Cdk4}

We reconstructed pcDNA 4/TO (Invitrogen), a tetracycline-regulated expression plasmid, for coexpressing two genes. A fragment containing the inducible promoter, the multiple cloning site (MCS) and the transcription termination sequence in the vector was released by $M l u$ I and $P v u$ II restriction enzyme digestion, and the ends of the fragment were blunted with T4 polymerase. At the same time, we blunted the ends of the large fragment of the same vector digested from $B s p \mathrm{H}$ I, two sites of which located at both ends of the ampicillin resistance gene. Then the two end-blunted fragments were ligated to create an intermediate vector, in which two genes of interest could be inserted for inducible expression; and the Zeocin conferred the selective resistance gene in both mammalian and E. coli cells. The myc-tagged cyclin D2 gene and the myc-tagged truncated cyclin D2 fragment, together with the flag-tagged Cdk4 gene, were subcloned into both MCSs of the intermediate to generate the expression vectors $\mathrm{pcDC} / \mathrm{TO}$ and $\mathrm{pcDmC} / \mathrm{TO}$, respectively. The replacement and insert of these sequences were determined by restriction enzyme digest profile. NIH-3T3 cells and Hela cells were transfected with pcDNA6/TR (Invitrogen), a regulatory vector expressing tetracycline repressor (TeR), and selected with blasticidin $(5 \mu \mathrm{g} / \mathrm{ml})$ to create stable cell lines. The expression of the tetracycline-inducible gene in these lines was tested by transient transfection with the positive-control plasmid expressing $\beta$-galactosidase. Clones exhibiting no basal transcription and the highest level of $\beta$-galactosidase expression after the addition of tetracycline were selected to coexpress cyclin D2 and Cdk4 or truncated cyclin D2 and Cdk4 by transfection with $\mathrm{pcDC} / \mathrm{TO}$ or $\mathrm{pcDmC} / \mathrm{TO}$, respectively, and selected with Zeocin $(250 \mu \mathrm{g} / \mathrm{ml})$. The intermediate vector was transfected in parallel into corresponding TeR stable cell lines to generate controls. Tetracycline was added to cells to a final concentration of $1 \mu \mathrm{g} / \mathrm{ml}$ to induce the expression of target genes. 


\section{Cell proliferation and death assays and DNA replication determination}

For cell growth and death rate determination, stable cell lines were suspended at $10^{4}$ cells $/ \mathrm{ml}$ and seeded with tetracycline. The media were replaced every $48 \mathrm{hr}$ with fresh media containing tetracycline. Cells were counted with use of a hemacytometer every 2 days. Cell number before the addition of tetracycline was counted to establish a baseline count, and cells were split every 4 days to avoid cell confluence. The number of dead cells was quantified by flow cytometry (FACSCalibur, BD). Cell samples were harvested every $24 \mathrm{hr}$ after tetracycline treatment, and the nuclei were stained with propidium iodide (PI, $100 \mu \mathrm{g} / \mathrm{ml}$ ) for $10 \mathrm{~min}$ (Rodgers, 1998) before flow cytometry analysis.

We used ${ }^{3} \mathrm{H}$-thymidine incorporation for DNA synthesis determination and S-phase progress (Giunta and Pucillo, 1996). Stable cell lines were suspended in equal concentrations in media containing $0.1 \%$ FBS and tetracycline for $24 \mathrm{hr}$ to synchronize cells, and media was replaced with media containing $10 \%$ FBS and tetracycline to release cells from G1 arrest. Seven hr, 30 min after G1 release, $1 \mathrm{mCi}$ of ${ }^{3} \mathrm{H}$-thymidine was added to $2 \times 10^{5}$ cells. Aliquot samples were harvested every $2 \mathrm{hr}$ for $14 \mathrm{hr}$, and liquid scintillation counting was performed. Duplicate samples were stained with PI for flow cytometry DNA content analysis at the same time points. All experiments were performed in triplicate.

\section{Immunoblotting, immunoprecipitation and immunofluorescence analysis}

Assays were carried out as described previously (Chen et al., 1998; Zhang et al., 2004) to analyze the expression, interaction and subcellular localization of the targeted proteins detected with anti-myc antibody for myc-cyclin D2 and the myc-truncated cyclin D2, antiflag for flag-Cdk4, and anti-HA for HA-pRb, HA-Lamin B and HA-Nup153. Bromodeoxyuridine (BrdU) labeling and immunofluorescence were performed to determine DNA synthesis. Before fixation, cells were incubated in medium containing $40 \mu \mathrm{M} \mathrm{BrdU}$ and $10 \mu \mathrm{M}$ fluorodeoxyuridine for $10 \mathrm{~min}$. Immunofluorescence analysis involved restriction digestion to create single-stranded regions in the DNA with anti-BrdU as described (Fox et al., 1991). Anti-myc tag and anti-cyclin D2 (M-20) antibodies were purchased from Santa Cruz Biotechnology (Santa Cruz, CA), anti-flag tag and anti-HA tag antibodies were from Upstate Biotechnology (NY), anti-BrdU antibody was from Roche, and anti-Cdk4 antibody (C8218) was from Sigma-Aldrich (St. Louis, MO). Immunofluorescence images were acquired by use of an Olympus FluoView 500 confocal microscope system (Olympus Japan) in the $\mathrm{XYZ}$ scanning mode by adjusting the stacked thickness of XY planes through the $\mathrm{Z}$ axis to observe appropriate spaces of the cells.

\section{Results}

\section{Cyclin D2 interacts with Cdk4 in vivo}

From human cDNA, we amplified the full-length cyclin D2 and Cdk4 genes and an N-terminal truncated cyclin D2 fragment, which contained the repeated $\mathrm{CBF}$ region but not the $\mathrm{L} \times \mathrm{C} \times \mathrm{E}$ motif and the N-terminal helix (Fig. 1A). The $\mathrm{CBF}$ repeat is required for cyclins to bind to Cdks (Jeffrey et al., 2000) and the $\mathrm{L} \times \mathrm{C} \times \mathrm{E}$ motif contributes the binding site for the $\mathrm{pRb}$ substrate (Ewen et al., 1993), whereas the N-terminal helix confers a second step of cyclin and Cdk interaction and exposure of the T-loop of the Cdk for phosphorylation (Card et al., 2000; Goda et al., 2001; Morris et al., 2002). Therefore, the truncated D2C4 complex would not be able to bind to and phosphorylate $\mathrm{pRb}$ or initiate DNA synthesis.

We characterized the interaction of cyclin D2 with Cdk4 by a yeast two-hybrid system. The full-length cyclin D2 gene and the truncated cyclin D2 fragment were constructed to yield two $\mathrm{BD}$ constructs, and the Cdk4 gene was subcloned to yield an AD construct. The two BD constructs were each cotransformed with the AD construct into yeast. Cotransformants containing the full-length cyclin D2 and Cdk4 genes could grow on the minimal SD medium lacking Trp and Leu and on the medium lacking Trp, Leu and His and showed evidence of $\beta$-galactosidase activity, whereas cotransformants containing the truncated cyclin D2 fragment and $\mathrm{Cdk} 4$ gene grew vigorously only on the media lacking Trp and Leu and weakly on the medium lacking Trp, Leu and His as compared with positive and negative controls (Fig. 1B). Therefore, full-length cyclin D2 interacted with $\mathrm{Cdk} 4$, but the truncated cyclin D2 interacted weakly with Cdk4.

To validate these interactions, the full-length cyclin D2 gene and truncated cyclin D2 fragment were myc-tagged, and the Cdk4 gene was flag-tagged, and they were subcloned under the cytomegalovirus (CMV) promoter. The constructs were transfected or cotransfected into HEK293T cells for expression analyses (Fig. 1C) or immunoprecipitation analyses (Fig. 1D). The myc-cyclin D2 but not the truncated myc-cyclin D2 associated with flag-Cdk4, which was similar to results from yeast but with a higher detectable threshold.

\section{Coexpression of cyclin D2 and Cdk4 accelerates G1-S transition}

To express two proteins of interest in cells under tetracycline regulation, we reconstructed a vector containing two copies of the expression unit from pcDNA 4/TO for insertion of myc-cyclin D2 or myc-truncated cyclin D2 and flagCdk4 genes. Stable cell lines coexpressing myc-cyclin D2 and flag-Cdk4 or the truncated myc-cyclin D2 and flagCdk4 were created from NIH-3T3 and Hela cells expressing 

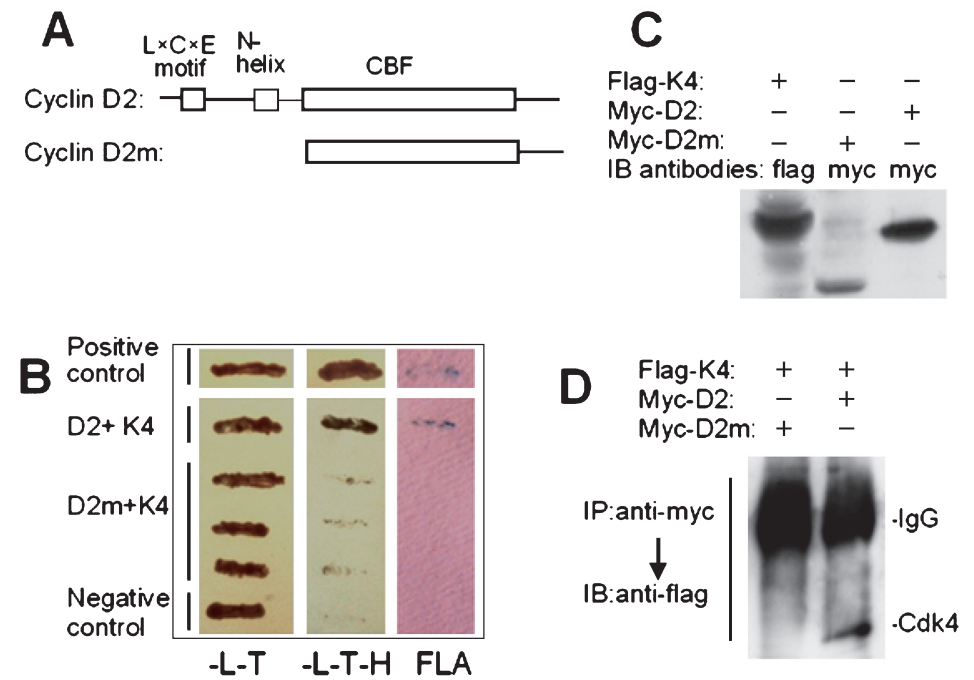

Fig. 1. Interaction of cyclin D2 with Cdk4. (A) Schematic representation of the full-length and truncated cyclin D2. (B) Yeast two-hybrid results showing full-length cyclin D2 strongly but truncated cyclin D2 weakly interacts with Cdk4. The left panel shows results from media lacking Leu and Trp (-L-T); the middle panel shows results from media lacking Leu, Trp and His (-L-T-H); the right panel shows results of filter lift assay (FLA) of $\beta$-galactosidase activity for colonies from the middle plate. (C) Expression of the epitope-tagged cyclin D2, truncated cyclin D2 and Cdk4 in HEK293T cells determined by protein immunoblotting. Cells were transfected with CMV plasmids expressing the indicated genes and harvested $48 \mathrm{hr}$ after transfection. Antibodies were used as indicated. (K4) Cdk4; (D2) cyclin D2; (D2m) the truncated cyclin D2 mutant. (D) Immunoprecipitation of flag-Cdk4 and myc-full length or myc-truncated cyclin D2. HEK293T cells were co-transfected with constructs as indicated and incubated for $48 \mathrm{hr}$ before harvest. The interactions were determined by anti-myc immunoprecipitation (IP) and anti-flag immunoblotting (IB).

TeR by transfection with corresponding constructs, as described in Materials and Methods. We selected for further experimentation an NIH-3T3 cell line and a Hela cell line coexpressing cyclin D2 and Cdk4 and an NIH-3T3 cell line and a Hela cell line coexpressing the truncated cyclin D2 and Cdk4 under tetracycline induction (Fig. 2A), as well corresponding control cell lines transfected with empty vector. Both NIH-3T3 and Hela cells coexpressing the fulllength cyclin D2 and Cdk4 showed a higher proliferation rate than controls and those coexpressing the truncated cyclin D2 and Cdk4 a lower proliferation rate (Fig. 2B). At day 12 , as compared with controls, the NIH-3T3 cell line coexpressing the full-length cyclin D2 and Cdk4 showed increased cell number, by $18.9 \%$, whereas that of the truncated cyclin D2 and Cdk4 showed decreased cell number, by $21.6 \%$; the corresponding changes in Hela cells were $12.1 \%$ and $25.3 \%$, respectively.

To explore the contribution of cyclin D2 and Cdk4 coexpression to accelerated cell proliferation, we determined DNA synthesis by ${ }^{3} \mathrm{H}$-thymidine incorporation in NIH-3T3 stable cells (Fig. 2C). Control cells entered the $\mathrm{S}$ phase between 10 and $12 \mathrm{hr}$ after FBS refeeding (G1 release) and completed DNA synthesis between 20 and $22 \mathrm{hr}$ after G1 release, whereas cells coexpressing the full-length cyclin D2 and Cdk4 initiated DNA synthesis about $2 \mathrm{hr}$ earlier and also completed the $\mathrm{S}$ phase faster. DNA synthesis in cells coexpressing truncated cyclin D2 and Cdk4 was similar to that in control cells. Flow cytometry results were consistent with those of ${ }^{3} \mathrm{H}$-thymidine incorporation (Table I). At the indicated time points after $\mathrm{G} 1$ release, the fraction with replicating DNA (3C DNA content) and replicated DNA (4C DNA content) in cells coexpressing the full-length cyclin D2 and Cdk4 was higher than that in control cells. Correspondingly, DNA replication in cells coexpressing the truncated cyclin D2 and Cdk4 was similar to that in control cells. Thus, increased proliferation rate in cells coexpressing cyclin D2 and Cdk4 resulted from accelerated S-phase entry. Therefore, the overexpressed proteins played their roles in these cells and the time of the G1-S transition of these cells was confirmed at about $10 \mathrm{hr}$ after FBS refeeding.

To understand the reduced proliferation rate in cells coexpressing the truncated cyclin D2 and Cdk4, we counted dead cells every $24 \mathrm{hr}$ after tetracycline induction in stable NIH-3T3 cells. The proportion of dead cells increased greatly and reached $5.15 \%$ at day 4 , whereas that in cells coexpressing full-length cyclin D2 and Cdk4 or in control cells remained low and reached only $1.92 \%$ and $1.17 \%$, respectively, at day 4 (Fig. 2D). Furthermore, confocal microscopy visualization of Hela stable cells by immunofluorescence with anti-myc and anti-flag antibodies revealed $8.5 \%$ of cells coexpressing the truncated cyclin D2 and Cdk4 showing nuclear collapse after induction for $48 \mathrm{hr}$ but no nuclear collapse in cells coexpressing the full-length cyclin D2 and Cdk4 (Table II; Fig. 2E). Therefore, the restraint on cell proliferation rate in cells with the truncated cyclin D2 and Cdk4 was via inducing cell death by an unknown mechanism. 


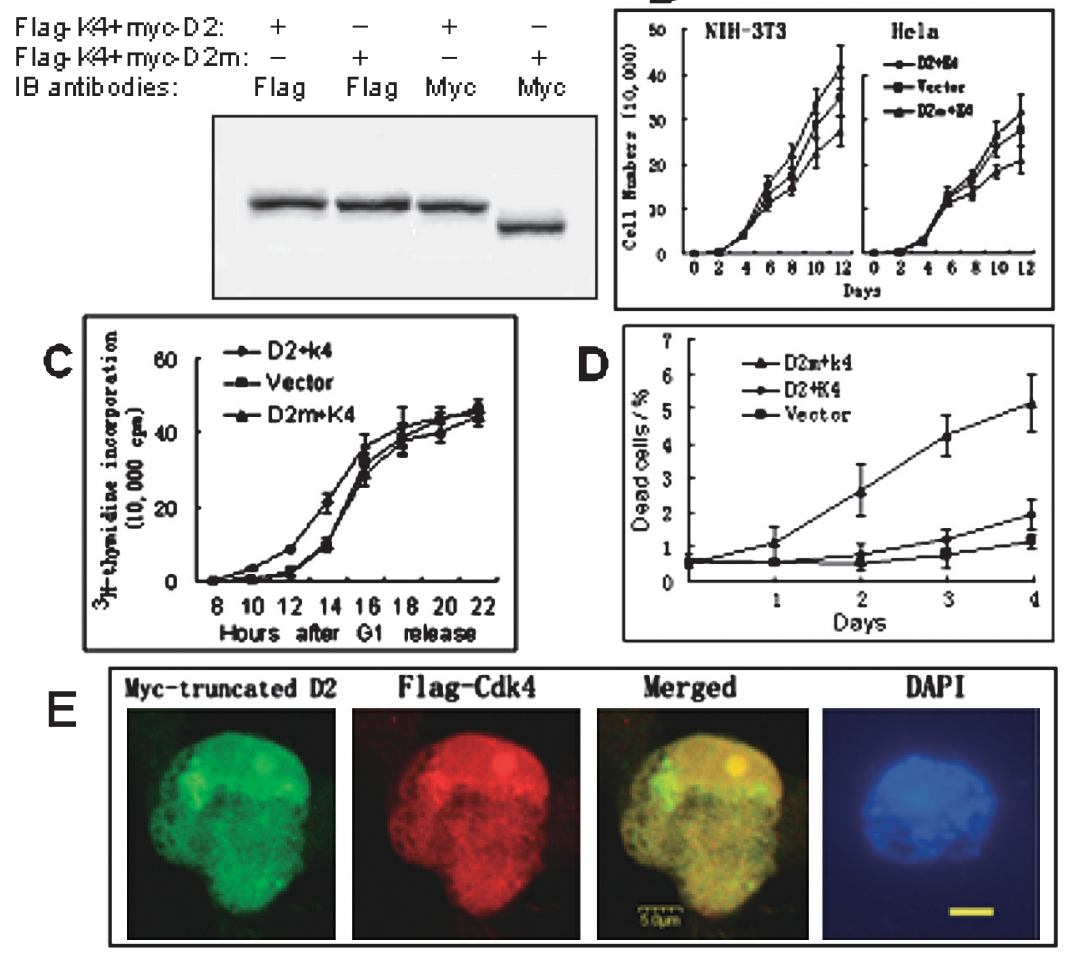

Fig. 2. Co-expression of cyclin D2 and Cdk4 accelerates cell proliferation through accelerating the G1-S transition. (A) Western blotting results showing the coexpression of the myc-cyclin D2 or the truncated myc-cyclin D2 and flag-Cdk4 in two stable cell lines. Lysates from stable Hela cells coexpressing different proteins and antibodies are indicated above the panel. Cells were induced with $1 \mu \mathrm{g} / \mathrm{ml}$ tetracycline for $36 \mathrm{hr}$ before harvest. Amounts of protein loaded were $25 \mu \mathrm{g}$ per lane. (B) Coexpression of full-length myc-cyclin D2 and flag-Cdk4 accelerate cell proliferation but that of truncated myc-cyclin D2 and flag-Cdk4 decelerate cell proliferation in stable NIH-3T3 and Hela cells. The densities of different cell lines were equalized before supplementing with tetracycline. The growth rates were determined by measuring the increase in cell number during subcultivation. (C) Coexpression of full-length cyclin D2 and Cdk4 accelerates initiation of DNA synthesis but that of truncated cyclin D2 and Cdk4 does not in stable NIH-3T3 cells. Equal amounts of cells were incubated with tetracycline and $0.1 \%$ FBS to synchronize them for $24 \mathrm{hr}$ and then $10 \%$ FBS to release them from G1 arrest. ${ }^{3} \mathrm{H}$-thymidine was added to cells $7.5 \mathrm{hr}$ after FBS stimulation. DNA synthesis was determined by measuring ${ }^{3} \mathrm{H}$-thymidine incorporation at the indicated times after $\mathrm{G} 1 \mathrm{release}$. (D) Coexpression of the truncated cyclin D2 and Cdk4 leads to increased cell death. Stable NIH-3T3 cell lines were incubated with tetracycline, and samples were collected every $24 \mathrm{hr}$. The viable and dead cells were counted by flow cytometry for 4 days. (E) Cell death was achieved by inducing nuclear-envelope collapse if too many truncated complexes escaped into the nucleus. Stable Hela cells coexpressing the truncated myc-cyclin D2 and flag-Cdk4 were fixed 48 hr postinduction, and immunofluorescence was visualized with use of anti-myc and anti-flag antibodies on confocal microscopy. (D2) full-length cyclin D2; (D2m) truncated cyclin D2; (K4) Cdk4; (HAR) hours after G1-phase release. Bar=5 $\mu \mathrm{m}$.

Table I. Percentage of CELlS With 3C AND 4C DNA CONTENT AFter G1 RELEASE IN NIH-3T3 CELLS

\begin{tabular}{lccrccccc}
\hline & \multicolumn{8}{c}{ Hours after G1 release } \\
\cline { 2 - 9 } & 8 & 10 & \multicolumn{1}{c}{12} & \multicolumn{1}{c}{14} & \multicolumn{1}{c}{16} & 18 & 20 & 22 \\
\hline D2+K4 & 1.6 & 6.3 & 14.7 & 36.6 & 68.9 & 91.2 & 89.0 & 79.4 \\
Vector & 0.0 & 2.2 & 4.5 & 19.7 & 61.6 & 85.3 & 89.5 & 83.4 \\
D2m+K4 & 0.0 & 1.8 & 5.4 & 21.4 & 58.8 & 85.7 & 87.7 & 82.8 \\
\hline
\end{tabular}

D2, myc-cyclin D2; D2m, the truncated myc-cyclin D2; K4, flag-Cdk4.
Table II. Subcellular Localization PATtERnS OF THE FULL-LENGTH AND TRUNCATED CYCLIN D2-Cdk4 COMPLEX IN HELA CELLS

\begin{tabular}{lrrrrrr}
\hline \multirow{2}{*}{ Localization } & \multicolumn{2}{c}{ D2/Cdk4 } & & \multicolumn{2}{c}{ D2m/Cdk4 } \\
\cline { 2 - 3 } \cline { 6 - 7 } & Cell no. & $\%$ & & Cell no. & $\%$ \\
\hline Cytoplasm & 104 & 27.1 & & 79 & 23.2 \\
Nuclear envelope & 97 & 25.3 & & 138 & 40.6 \\
Chromatin & 95 & 24.7 & & 0 & 0 \\
Nucleolus & 88 & 22.9 & & 39 & 11.5 \\
Nucleoplasm & 0 & 0 & & 55 & 16.2 \\
Broken nucleus & 0 & 0 & & 29 & 8.5 \\
\hline \multicolumn{1}{c}{ Total } & 384 & 100 & 340 & 100 \\
\hline
\end{tabular}

D2, myc-cyclin D2; D2m, the truncated myc-cyclin D2 


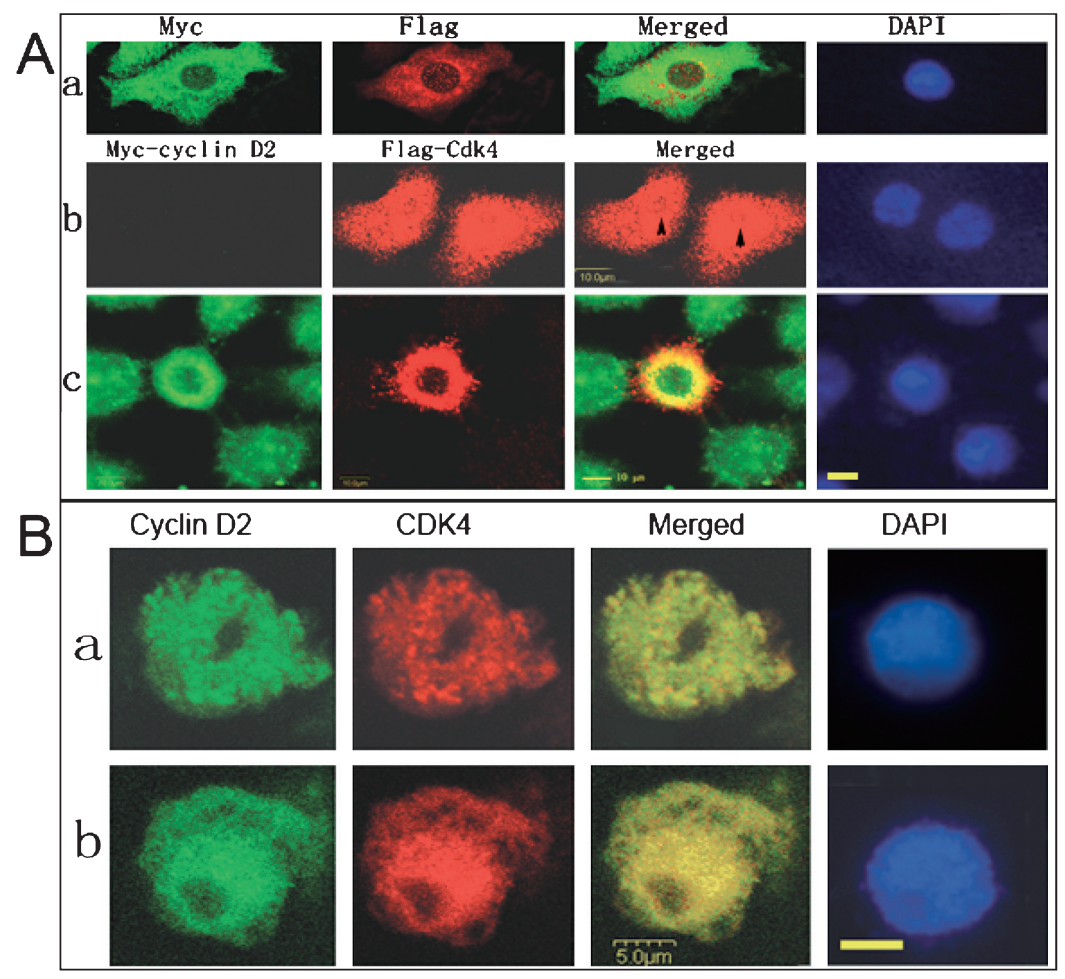

Fig. 3. Nuclear imports of cyclin D2 and Cdk4 are in a concomitant pattern. (A) Nuclear approach requires equal expression of cyclin D2 and Cdk4 in transient transfected Hela cells. a) Coexpressed myc tag and flag tag localize in the cytoplasm but not in the nucleus in cells cotransfected with pCMV-4myc and pCMV-4flag; stacked space spans the nuclear middle. b) Singly expressed flag-Cdk4 dispersed near the nucleus; stacked thickness covers the top of the nucleus. Holes at the arrowhead show tops of the nucleus. c) Singly expressed myc-cyclin D2 dispersed in cells (cells around the central cell); an equal amount of the myc-cyclin D2 and flag-Cdk4 colocalized and accumulated around the nucleus, but excess flag-Cdk4 stayed in situ in the coexpressing cell (the cell at center; stacked planes span nuclear central section). Cells were transfected simultaneously with pCMV-myc-cyclin D2 and pCMV-flag-Cdk4; immunofluorescence was assayed $36 \mathrm{hr}$ after transfection by use of anti-myc and anti-flag antibodies on confocal microscopy. Bar=10 $\mu \mathrm{m}$. (B) Nuclear imports of endogenous cyclin D2 and Cdk4 show a concomitant pattern in NIH-3T3 cells. a) Cyclin D2 and Cdk4 localize outside the nucleus; the stacked planes are across the nuclear central section; b) on localization into the nucleus, the stacked planes span to the top of the nucleus. Cyclin D2 and Cdk4 were analyzed by immunofluorescence assay with antibodies against cyclin D2 and Cdk4 on confocal microscopy. The nuclear DNA was counterstained with DAPI. Bar $=5 \mu \mathrm{m}$.

\section{Nuclear approach of cyclin D2 and Cdk4 exhibits a cotransferrance behavior}

To observe the subcellular localization patterns of single expression or coexpression of myc-cyclin D2 and flag-Cdk4 in cells, Hela cells were transfected at the same time with two constructs subcloned with myc-cyclin D2 gene or flagCdk4 gene, respectively. At the same time, cells were co-transfected with two vectors each inserted with only 4 tandem copies of the myc or the flag tags, which served as a control. The localization of the tagged proteins was assayed by immunofluorescence assay with anti-myc and anti-flag antibodies on confocal microscopy. The second antibody against myc was a FITC conjunction and that against flag was a TRITC conjunction.

The myc tags and flag tags in control cells were expressed in the cytoplasm but not in the nucleus, and both signals were not superimposed (Fig. 3A-a). Similarly, in cells transfected with only a single construct, flag-Cdk4 (Fig. 3A-b) or myc-cyclin D2 (Fig. 3A-c surrounding cells) alone was dispersed in the cytoplasm. At all times, if myccyclin D2 and flag-Cdk4 were co-expressed in a cell, they localized together and co-accumulated around the nuclei (Fig. 3A-c, cell at center) or in the nuclei (see below). Interestingly, if flag-Cdk4 showed greater expression than myccyclin D2 in a cell (Fig. 3A-c, cell at center), the excess Cdk4 stayed in situ but the colocalized pairs approached the nucleus. These data and that from interactional assays suggested that myc-cyclin D2 bound to flag-Cdk4 forming a complex in cells and achieved the ability of nuclear import.

To validate that endogenous cyclin D2 and Cdk4 shared the same patterns of nuclear localization as the overexpressed proteins in Hela cells, fixed wild-type NIH-3T3 cells underwent immunofluorescence assay with use of anticyclin D2 and anti-Cdk4 antibodies. Cyclin D2 and Cdk4 colocalized around the nucleus (Fig. 3B-a) or from outside 
to inside the nucleus (Fig. 3B-b), which also indicates a cotransfer behavior of endogenous cyclin D2 and Cdk4 in cells.

\section{Nuclear import of the D2C4 complex is step-wise}

To further dissect this migratory process, we analyzed the translocalization pattern of the tagged cyclin D2 and Cdk4 (D2C4) complex in Hela cells, which displayed a more distinct interface of nuclear membrane than NIH-3T3 cells in our experiments. Immunofluorescence assay of cells coexpressing myc-cyclin D2 and flag-Cdk4 were visualized by confocal microscopy. We individually sorted 384 cells from three independent experiments and found that the localization profiles of the complex were different from cell to cell. We grouped the localization of the complex into 4 patterns: in the cytoplasm, on the nuclear membrane, in the nucleus and in the nucleolus, for approximately one-quarter of cells in each group (Table II), which suggested that the localization of the D2C4 complex was dynamic.

On the basis of the sizes of nucleus, the translocalization order should be from the cytoplasm to the nucleus. With small nuclei, the $\mathrm{D} 2 \mathrm{C} 4$ complex docked outside the nuclear membrane within a layer of about $2-3 \mu \mathrm{m}$ thick (Fig. 4a). With large nuclei, the complex localized at the nuclear membrane (Fig. 4b). Then, the complexes were arrested on the nuclear membrane (Fig. 4b, 4c). To confirm this localization on the nuclear membrane, we tagged a lamin B gene, encoding a nuclear membrane-associated protein, with HA epitope. Hela cells coexpressing myc-cyclin D2 and flagCdk4 were transfected with pCMV5-HA-lamin B. Myccyclin D2 and HA-lamin B underwent immunofluorescence analysis with anti-myc and anti-HA antibody, respectively. The nuclear membrane was visualized by use of TRITC antibody, and the D2C4 complex colocalized with the lamin $\mathrm{B}$ on the nuclear membrane (Fig. 4f). More importantly, the complex was arrested on the nuclear membrane and did not escape continuously into the nucleus (Fig. 4c), which suggested that an intermediate step was necessary for the nuclear import process. Finally, the complex was completely released into the nucleus after the arresting step (Fig. $4 c-e)$. After being released from the nuclear membrane, the complex localized in the nuclei or at the chromatin, which showed a characteristic profile of heterochromatin clumps (Fig. 4e; Leblond et al., 1998).

This translocalization pattern was also observed in NIH3 T3 cells coexpressing cyclin D2 and Cdk4. These cells underwent synchronized arrest and were analyzed by immunofluorescence assay at 8 and $16 \mathrm{hr}$ after FBS refeeding. Cells showed the D2C4 complex localized out of the nucleus before G1-S transition and in the nucleus after the transition (see below; Table III). The endogenous cyclin D2 and $\mathrm{Cdk} 4$ also showed a similar pattern of translocalization (Fig. 3B).
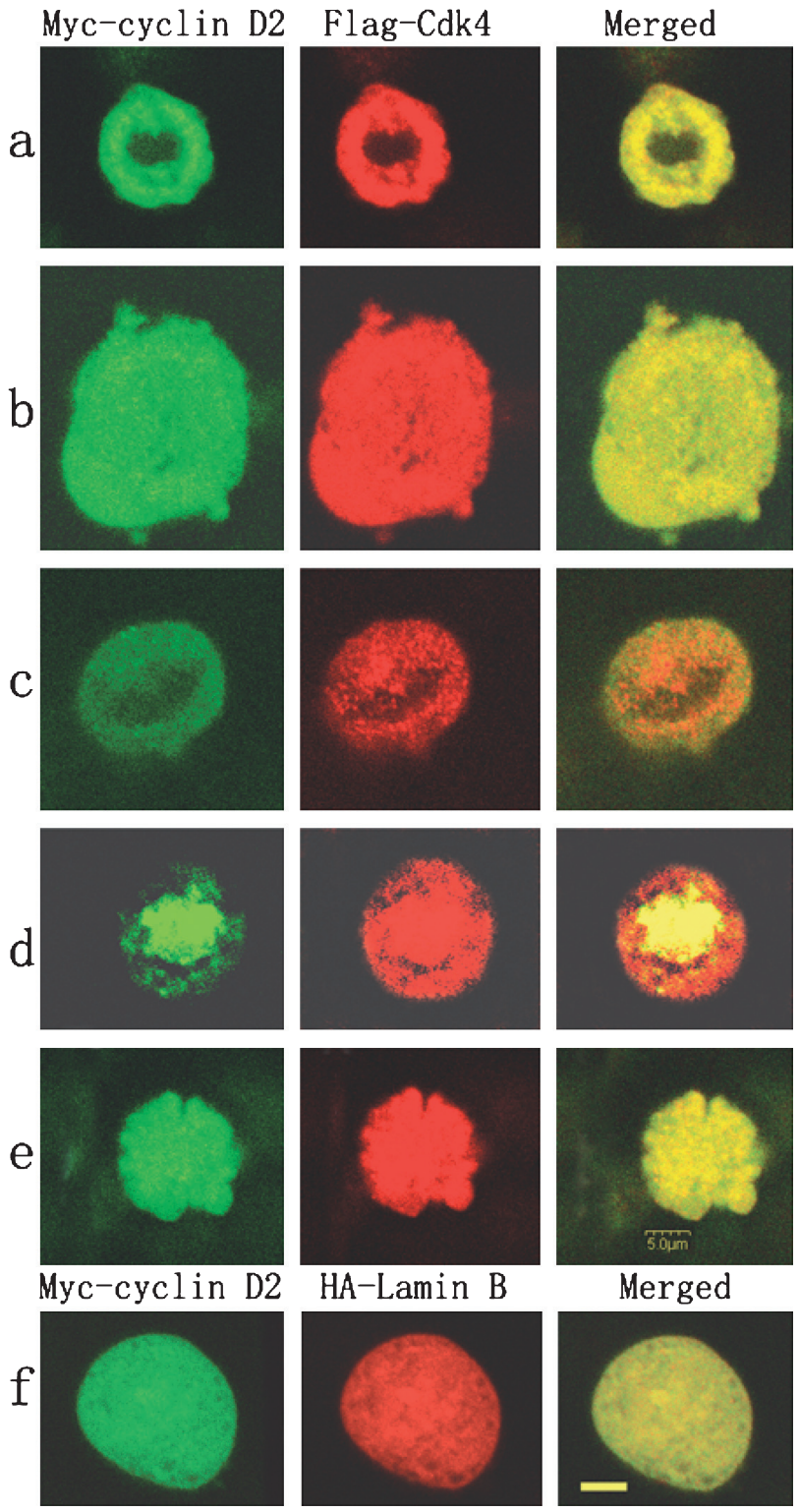

Merged

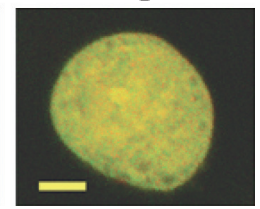

Fig. 4. Nuclear import of the D2C4 complex is step-wise. a) D2C4 complex accumulates around the nucleus before the nucleus reaches a critical size; the stacked planes span the central section of the nucleus; b) D2C4 complex at the nuclear membrane from one pole of the nucleus to another when the nucleus is large ( $22 \mu \mathrm{m}$ in diameter); the stacked planes span the upside of the nucleus; c) D2C4 complex arrested on the nuclear membrane; the stacked planes span the upside of the nucleus; d) D2C4 complex released from the nuclear membrane into the nucleus; the stacked planes span the upside of the nucleus; and e) D2C4 complex localizes in the nucleus; the stacked planes span the central section of the nucleus. Stable Hela cells were induced by tetracycline for $36 \mathrm{hr}$. Immunofluorescence assay of cells with use of anti-myc and anti-flag antibodies on confocal microscopy. f) Immunofluorescence assay of nuclear membrane with HA-lamin B; the stacked planes span the upside of the nucleus. Stable Hela cells were transfected with pCMV-HA-lamin B for $24 \mathrm{hr}$ and induced by tetracycline for another $24 \mathrm{hr}$; immunofluorescence was visualized with use of anti-myc and anti-HA antibodies. Bar $=5 \mu \mathrm{m}$. 
Table III. LOCALIZATION OF THE FULL-LENGTH AND TRUNCATED D2C4 COMPLEX 8 AND 16 HOURS AFTER RELEASE FROM SYNCHRONIZED ARREST IN NIH-3T3 CELLS

\begin{tabular}{|c|c|c|c|c|c|c|c|c|}
\hline \multirow{3}{*}{ Localization } & \multicolumn{4}{|c|}{$\mathrm{D} 2 / \mathrm{Cdk} 4$} & \multicolumn{4}{|c|}{$\mathrm{D} 2 \mathrm{~m} / \mathrm{Cdk} 4$} \\
\hline & \multicolumn{2}{|c|}{$8 \mathrm{HAR}$} & \multicolumn{2}{|c|}{16 HAR } & \multicolumn{2}{|c|}{$8 \mathrm{HAR}$} & \multicolumn{2}{|c|}{16 HAR } \\
\hline & Cell no. & $\%$ & Cell no. & $\%$ & Cell no. & $\%$ & Cell no. & $\%$ \\
\hline Out of the nucleus & 119 & 77.3 & 42 & 28.4 & 65 & 80.2 & 79 & 68.1 \\
\hline In the nucleus & 35 & 22.7 & 106 & 71.6 & 16 & 19.8 & 37 & 31.9 \\
\hline Total & 154 & 100 & 148 & 100 & 81 & 100 & 116 & 100 \\
\hline
\end{tabular}

D2, myc-cyclin D2; D2m, the truncated myc-cyclin D2; K4, flag-Cdk4; HAR, hours after release from synchronous arrest.

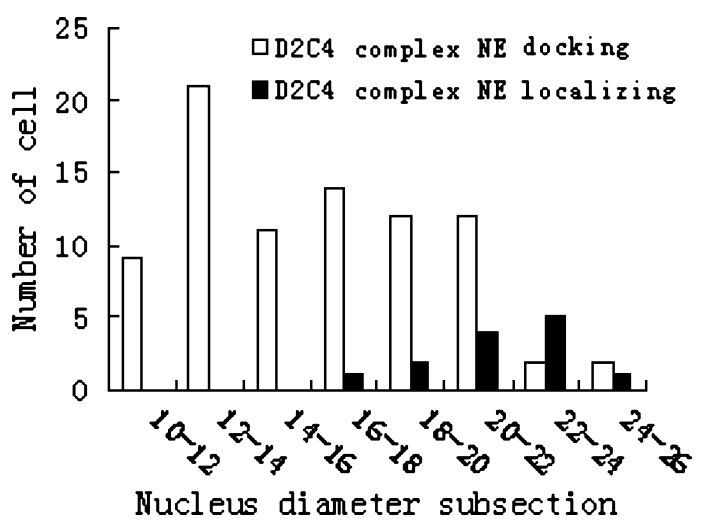

Fig. 5. Nuclear membrane localization of the D2C4 complex for nuclear import depends on nucleus size. The frequency distributions of D2C4 complex NE docking or NE localizing in different intervals of nucleus diameter $(\mu \mathrm{m})$ are shown.

\section{Nuclear import of D2C4 complex depends on nucleus size}

To address the dependence of the nuclear import of the complex on the nucleus size we measured the diameter of nuclei before releasing the complex into the nucleus from the nuclear envelope (NE), the space which might include the docking layer close to the nucleus. These nuclei exhibited D2C4 complex either NE docking (see below) or NE localizing (Fig. 4b). The frequency distribution of both nuclei in different intervals of nucleus diameter indicated that nuclei localized the complex at nuclear membrane at large size $(20-24 \mu \mathrm{m})$ and docked the complex close to the $\mathrm{NE}$ at small size (10-22 $\mu \mathrm{m})$ (Fig. 5). It suggested that cells needed an upgrowth for nucleus preparation to initiate cell division and that the $\mathrm{D} 4 \mathrm{C} 2$ complex was allowed nuclear import only at reaching a critical nuclear size.

\section{The D2C4 complex accumulated in front of the nuclear pore before nuclear import}

To investigate the docking pattern of the $\mathrm{D} 2 \mathrm{C} 4$ complex on the nuclear membrane, cells with small nuclear size were examined on immunofluorescence assay. When the com-

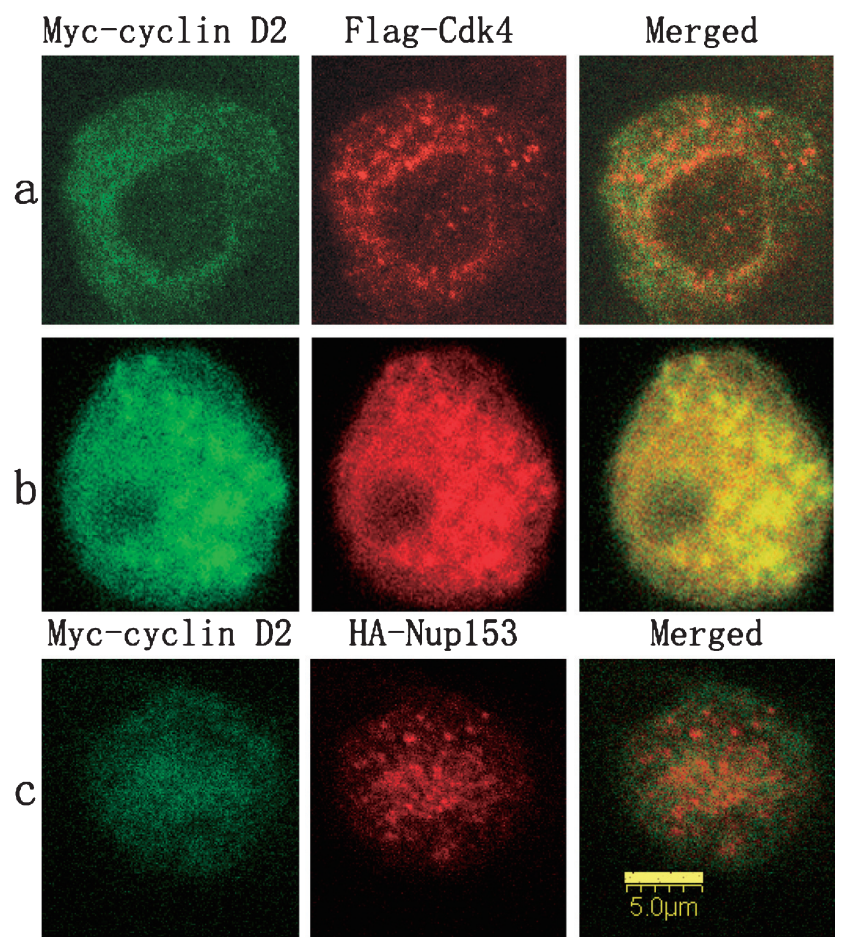

Fig. 6. The D2C4 complex gathers at the cytosolic surface of the nuclear pores at the early stage of docking. a) Docking mode when the size of the nucleus is about $12 \mu \mathrm{m}$ in diameter; the stacked planes span the upside of the nucleus. b) D2C4 complex accumulates at the nuclear pore complexes more than on the lipid membrane; the stacked planes span the upside of the nucleus. c) HA-tagged Nup153 shows the NPCs on the nuclear membranes; the stacked planes span the top of the nucleus. Stable Hela cells were transfected with pCMV-HA-Nup153 for $24 \mathrm{hr}$ and induced to coexpress myc-cyclin D2 and flag-Cdk4 for another $24 \mathrm{hr}$; immunofluorescence was visualized with use of anti-myc and anti-HA antibodies on confocal microscopy. Bar $=5 \mu \mathrm{m}$.

plex emerged on the NE the nucleus was approximately 12 $\mu \mathrm{m}$ in diameter (Fig. 6a), which was only one-sixth of the largest apparent volume. At this time, the complex docked preferentially on the cytosolic surface of the nuclear pores to the lipid membrane area (Fig. 6a-b), but the distribution showed a trend to uniformity with increasing accumulation 
to form a thick docking layer (Fig. 6b). To confirm the nuclear pore, we tagged the Nup153 gene, encoding a component of the nuclear pore complex (NPC) (Ball and Ullman, 2005), with HA. Cells coexpressing myc-cyclin D2 and flag-Cdk4 were transfected with pCMV5-HANup153, and myc-cyclin D2 and HA-Nup153 underwent immunofluorescence assay with anti-myc and anti-HA, respectively. The NPCs were visualized by HA-Nup153 localization and the NPCs and myc-cyclin D2 localized at the NE (Fig. 6c).

\section{Translocalization of the D2C4 complex depends on the G1-S transition}

To investigate whether the translocalization of the $\mathrm{D} 2 \mathrm{C} 4$ complex depended on the G1-S transition, we analyzed the localization patterns before and after the transition by immunofluorescence assay on confocal microscopy. Stable NIN-3T3 cells were synchronized, and coexpression of myc-cyclin D2 and flag-Cdk4 was induced, then cells were stimulated to release them from the G1 arrest. Cells were fixed at $8 \mathrm{hr}$ or $16 \mathrm{hr}$ after stimulation, representing before or after the G1-S transition, respectively (Table I; Fig. 2C). The localization of the complex in cells showed two patterns: out of the nucleus and in the nucleus (Table III). Before the G1-S transition, for $77.3 \%$ of cells expressing the full-length D2 and Cdk4, the complex was localized out of the nucleus, and for only $22.7 \%$, the complex was localized in the nucleus. In contrast, after the transition, only $28.4 \%$ of cells showed the complex localized out of the nucleus, and in $71.6 \%$, the complex was localized in the nucleus. This localization of the complex outside the nucleus before the G1-S transition but inside the nucleus after the transition further suggested that the nuclear import depended on the G1-S transition.

\section{D2C4 complex phosphorylates $p R b$ after release into the nucleus}

$\mathrm{pRb}$ localizes predominantly in the euchromatic areas around the heterochromatin clumps during the G1 phase (Mittnacht and Weinberg, 1991; Szekely et al., 1991), to where the D2C4 complex seemed to localize after release from the nuclear membrane (Fig. 4e). The colocalization might allow the complex to access pRb since the DC complexes can form complexes with pRb (Kato et al., 1993; Ewen et al. 1993). Phosphorylation of pRb by the DC complex at the G1-S boundary (Buchkovich et al., 1989; Chen et al., 1989) allows for the G1-S transition (Lundberg et al., 1998; Chen et al., 1989).

To confirm this hypothesis, we transfected stable NIH3T3 cells with pCMV5-HA-Rb and induced coexpression of myc-cyclin D2 and flag-Cdk4. The localization of myccyclin D2 and HA-pRb was observed with use of anti-myc and anti-HA on immunofluorescence assay. Cyclin D2 localized outside the nucleus and $\mathrm{pRb}$ localized in the nucleus when the nuclei size was small, $14 \mu \mathrm{m}$ in diameter (Fig. 7A-a), but colocalized with $\mathrm{pRb}$ and was superimposed with chromatin DNA in the nucleus when the chromatin region size was greater than $16 \mu \mathrm{m}$ in diameter (Fig. 7A-b). Therefore, the D2C4 complex was separated from the $\mathrm{pRb}$ by the nuclear envelope before nuclear import but accessed the $\mathrm{pRb}$ after release into the nucleus.

To analyze the phosphorylation form of $\mathrm{pRb}$ before and after colocalization with the D2C4 complex, lysates from synchronized NIH-3T3 cells coexpressing HA-pRb, myccyclin D2 and flag-Cdk4 at 8 and $16 \mathrm{hr}$ after FBS stimulation underwent immunoblotting with anti-HA antibody. $\mathrm{pRb}$ was phosphorylated after but not before the G1-S transition (Fig. 7B). Thus, the D2C4 complex colocalized with and phosphorylated $\mathrm{pRb}$ after release into the nucleus.

To further pursue whether colocalization of the complex with $\mathrm{pRb}$ on the chromatin related to DNA synthesis, cells expressing myc-cyclin D2 and flag-Cdk4 were analyzed by BrdU incorporation and immunofluorescence assay. Localization of the D2C4 complex at the chromatin occurred with DNA synthesis (Fig. 7A-c). Therefore, DNA replication was closely related to the localization of the D2C4 complex to chromatin after the complex was released from the nuclear membrane.

\section{Release from the nuclear membrane requires an intact complex}

The full-length D2C4 complex was released into the nucleus after arrest on the nuclear membrane. However, the truncated complex was persistently arrested on the nuclear membrane even though the myc-truncated cyclin D2 colocalized with the flag-Cdk4, which indicated their association in cells (Fig. 2E). In synchronous NIH-3T3 cells with the truncated D2C4 complex expression, before the G1-S transition, $80.2 \%$ of cells accumulated the complex on the nuclear membrane and $19.8 \%$ of cells appeared to have leaked some complexes into the nucleus (Table III), but after the transition, $68.1 \%$ of cells still showed the complex arrested on the membrane and only $31.9 \%$ of cells showed some of the complexes leaked into the nucleus. In contrast, $71.6 \%$ of the cells expressing the full-length complex released all of the complexes into the nuclei at the same time after the G1-S transition. Furthermore, $40.6 \%$ of Hela cells expressing the truncated complex arrested the complex on the nuclear membrane, as compared with only $25.3 \%$ of cells with the full-length complex after tetracycline induction (Table II). Of note, no cell released all its truncated complexes into the nucleus and few of the truncated complexes specifically localized at the chromatin as compared to the full-length complexes (Table II). Obviously, the truncated complex was locked on the nuclear membrane, only because the cyclin D2 subunit was $\mathrm{N}$-terminal truncated. Thus, it required an intact complex for release. 

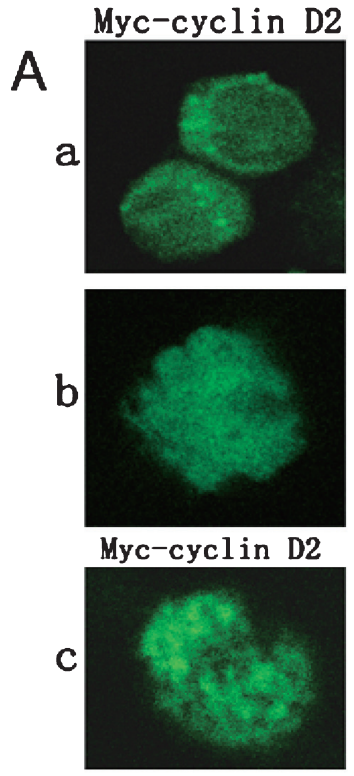
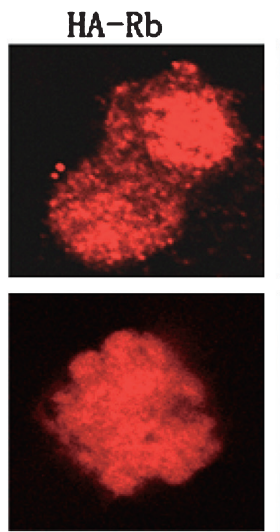

BrdU

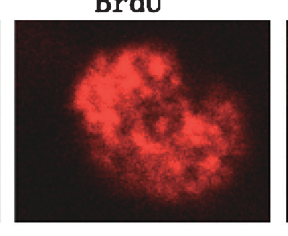

Q Myc-D2+flag-K4:+

$\begin{array}{llll}\text { HA-Rb: } & + & + & - \\ \text { HAR: } & 8 & 16 & 8 \\ \text { Antibodies: } & \text { HA } & \text { HA } & \text { HA }\end{array}$
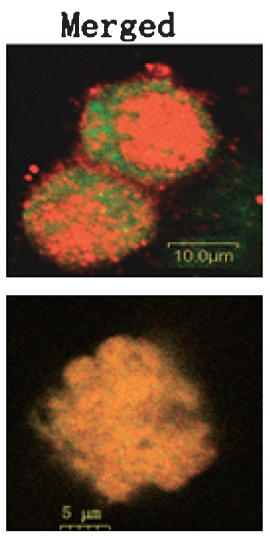

Merged

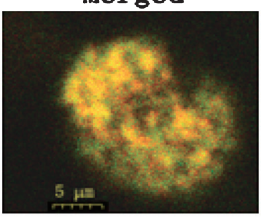

HA

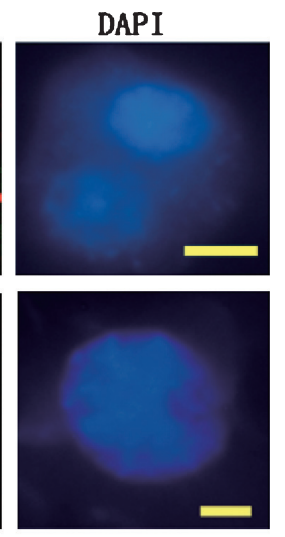

DAPI

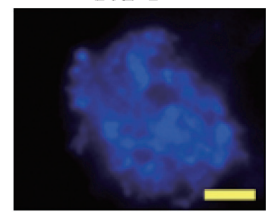

\begin{tabular}{|lll|}
\hline $\mathrm{HeRb}$ & \\
$\mathrm{HoRb}$ & -118 & $\mathrm{kDa}$ \\
& -86 & $\mathrm{kDa}$
\end{tabular}

Fig. 7. Localization and activity analyses of $\mathrm{D} 2 \mathrm{C} 4$ complex. (A) Colocalization of $\mathrm{D} 2 \mathrm{C} 4$ complex with pRb. a) D2C4 complex and pRb localize outside and inside the nucleus, respectively, before the $\mathrm{D} 2 \mathrm{C} 4$ complex nuclear import; the stacked planes span the central section of the nucleus. Bar=10 $\mu \mathrm{m}$. $\mathrm{b}$ ) $\mathrm{D} 2 \mathrm{C} 4$ complex and the pRb colocalize at nuclear chromatin DNA after nuclear import; the stacked planes span the central section of the nucleus. Stable NIH-3T3 cells were transfected with pCMV-HA-Rb for $24 \mathrm{hr}$ and supplemented with tetracycline for another $24 \mathrm{hr}$; immunofluorescence was assayed with use of anti-myc and anti-HA antibodies on confocal microscopy. Bar $=5 \mu \mathrm{m}$. c) Localization of the D2C4 complex and DNA synthesis are concurrent at chromatin; the stacked planes span the central section of the nucleus. Bar $=5 \mu \mathrm{m}$. Stable cells were induced with tetracycline for $24 \mathrm{hr}$ and supplemented with BrdU for $10 \mathrm{~min}$; myc-cyclin D2 analysis and BrdU incorporation by immunolocalization assay with use of anti-myc and anti-BrdU antibodies on confocal microscopy. The nuclear DNA was stained with DAPI. (B) pRb is phosphorylated after G1-S transition. Stable NIH-3T3 cells were transfected with pCMVHA-Rb for $24 \mathrm{hr}$ and synchronized, and coexpression of myc-cyclin D2 and flag-Cdk4 was induced for another $24 \mathrm{hr}$; cells were released from G1 arrest by FBS stimulation and harvested $8 \mathrm{hr}$ and $16 \mathrm{hr}$ after G1 release. pRb in the lysates was determined by immunoblotting with anti-HA antibody.

\section{Discussion}

Cyclin Ds assemble with Cdks to form DC complexes to associate with $\mathrm{pRb}$ for G1-S transition in the cell cycle. Our observations of the $\mathrm{D} 2 \mathrm{C} 4$ complex suggest a spatial model whereby the initiation of the G1-S transition is switched on by the $\mathrm{D} 2 \mathrm{C} 4$ complex being released from the nuclear membrane to access the $\mathrm{pRb}$ mediated by the NPC at the end of the G1 phase. The regulation is via a series of migratory steps of the complex from the cytoplasm to the chromatin. Among these steps, the localization at the nuclear membrane is critical because it depends on the size of the nucleus. Another critical step is the release of the complex from the nuclear membrane into the nucleus because it requires the intact cyclin D2. The release leads to $\mathrm{pRb}$ phosphorylation and DNA synthesis.

In the nucleus, DNA replication is one of the most rapid and accurate processes that takes place once during a cell cycle (Alberts et al., 2002). Co-expression of the full-length cyclin D2 and Cdk4 accelerates the G1-S transition, but overexpression of the truncated complex would lead to nuclear collapse if too much of the complex escapes into the nucleus, where it might take the place of the endogenous functional DC complex to extinguish the initiated cell cycle.

Cyclin D2 is expressed in cytoplasm as the cell responds to mitogenic signals and associates with $\mathrm{Cdk} 4$ (Sherr, 1993). The association promotes the interaction of the cyclin-Cdk complex with an inhibitor, which contains a nuclear localization signal thus forming a ternary complex for nuclear import (Jeffrey et al., 2000; LaBaer et al., 1997). The complex accumulates on the outer surfaces of the NPCs and the nuclear envelope until the nucleus reaches a threshold size. Here, the response to the size of the nucleus may be a mechanism similar to the response of the G1-S transi- 
tion to a critical size of the cell (Dolznig et al., 2004). Early on, cell division was observed to depend on the proportion of nuclear volume to cytoplasmic volume (the N/C ratio) (Prescott, 1956; Mitchison, 1971). As well, in metazoan embryonic development, the mid-blastula transition, which marks the initiation of zygotic gene transcription and the end of the embryo's dependency on maternal mRNA, occurs when the N/C ratio reaches a critical value (Edgar et al., 1986; Masui and Wang, 1998). In addition, an adult cell maintains a close relation not only between the size of the nucleus and the cytoplasmic volume but also in proportionality between cytoplasmic volume and the surface area of the nucleus (Swanson et al., 1991). These observations suggest that a critical size of cells is required for cell division. Similarly, the G1-S transition is initiated in response to the size of the nucleus.

In a cell, the nuclear envelope is a coat protecting the genomic material from the cytosolic metabolism, and the nuclear pores act as gates for nuclear protein transport. Import of nuclear proteins follows a sequential model whereby the proteins first bind to the distal part of the cytoplasmic filaments and then, at the cytoplasmic entry, to the central channel of the NPC before being translocated into the nucleus (Panté and Aebi, 1996). The nuclear import of cyclin B1- and cyclin E-Cdk complexes through nuclear pores are via distinct mechanisms. Cyclin E follows a classical mechanism for proteins containing a nuclear localization signal, but cyclin B1 is imported into the nucleus via direct interaction with a site in the NH2 terminus of importin- $\alpha$ (Moore et al., 1999). In addition, a membrane-associated Cdk inhibitory kinase, Myt1, can bind and sequester Cdk in the cytoplasm (Wells et al., 1999), but p27 interacts with both cyclin D and a nuclear pore-associated protein, mNPAP60 (Müller et al., 2000). The association of these cyclin-Cdk complexes with the importin, nucleoporin or membrane-associated proteins regulates the import of these complexes mediated by the NPC.

More importantly, the NPC can initiate an inhibitory mechanism through structural rearrangement to inhibit the import pathway during the cell cycle; it allows a transportinhibitory nucleoporin binding to karyopherin specifically to slow its movement through the nuclear pore (Makhnevych et al., 2003). During meiosis, the interaction domain of nucleoporin RanBP2/Nup358 controls the conjugation enzymes crossing the nuclear membrane so that the ubiquitin-related modifier and Rad 51 control the formation of the Rad51 foci for homologous recombination (Saitoh et al., 2002). Here, we show that the D2C4 complex is held up in front of the NPC and was arrested on the nuclear envelope before nuclear import to regulate G1-S transition by some unknown mechanism.

Further, an R-Smad mediated by nuclear transport machinery provides a regulatory step at the nuclear membrane through a physical interaction between an integral inner nuclear-membrane protein, MAN1, and the R-Smad to repress signaling of cytokines (Pan et al., 2005). Another integral inner-membrane protein, LAP2 $\beta$, interacts with a transcription factor at the nuclear membrane through a model of spatial separation of the transcription factor from its target promoters (Nili et al., 2001). Moreover, a growth factor interfaces with an integral membrane receptor on the outer nuclear envelope and associates with karyopherin to translocate through the nuclear pore, then localizes in the inner nuclear matrix and finally at the periphery of heterochromatin to modulate DNA activity (Zagon et al., 2002). Our functional D2C4 complex was arrested on the nuclear membrane and then released into the nucleus, but the dysfunctional complex was persistently arrested on the nuclear membrane by some unknown mechanisms. It suggests that regulatory mechanisms mediated by the nuclear membrane for nuclear import of various regulators are diversiform in cells.

$\mathrm{pRb}$ contributes the mechanism of the R-point switch of the G1-S transition (Lukas et al., 1996), and the DC complex-pRb pathway regulates various responses of checkpoint restriction, including cell cycle delay, cell cycle arrest and cell death (Zhou et al., 2000). The irreversible release of the D2C4 complex from the nuclear membrane into the nucleus to phosphorylate $\mathrm{pRb}$ and initiate DNA synthesis is consistent with the behavior of the R point of the G1-S transition.

Signaling molecules, growth factors, transcription factors, homologous recombination regulators and G1-S transition regulators need to associate with the nuclear membrane to separate from nuclear DNA. This spatial separation of regulatory factors from nuclear DNA mediated by the nuclear membrane is common in the regulation of gene expression and in the initiation of DNA replication.

Acknowledgments. We thank Prof. Yeguang Chen for the kind gifts of mammalian cell lines, expression vectors and technical support and Laura Heraty for carefully reading the manuscript. This work was supported by a grant from the Guangxi Guitang Group Co., Ltd., China.

\section{References}

Alberts, B., Johnson, A., Lewis, J., Raff, M., Roberts, K., and Walter, P. 2002. Molecular biology of the cell, 4th ed., New York: Garland Science, p.983-1062.

Baldin, V., Lukas, J., Marcote, M.J., Pagano, M., and Draetta, G. 1993. Cyclin D1 is a nuclear protein required for cell cycle progression in G1. Genes Dev., 7: 812-821.

Ball, J.R. and Ullman, K.S. 2005. Versatility at the nuclear pore complex: lessons learned from the nucleoporin Nup153. Chromosoma, 114: 319330.

Buchkovich, K., Duffy, L.A., and Harlow, E. 1989. The retinoblastoma protein is phosphorylated during specific phases of the cell cycle. Cell, 58: $1097-1105$.

Card, G.L., Knowles, P., Laman, H., Jones, N., and McDonald, N.Q. 2000. Crystal structure of a $\gamma$-herpesvirus cyclin-cdk complex. EMBO J., 19: 2877-2888.

Chen, P.L., Scully, P., Shew, J.Y., Wang, J.Y., and Lee, W.H. 1989. Phosphorylation of the retinoblastoma gene product is modulated during the cell cycle and cellular differentiation. Cell, 58: 1193-1198. 
Chen, Y.G., Hata, A., Lo, R.S., Wotton, D., Shi, Y.G., Pavletich, N., and Massague J. 1998. Determinants of specificity in TGF- $\beta$ signal transduction. Genes Dev., 12: 2144-2152.

Diehl, J.A., Cheng, M., Roussel, M.F., and Sherr, C.J. 1998. Glycogen synthase kinase-3 $\beta$ regulates cyclin D1 proteolysis and subcellular localization. Genes Dev., 12: 3499-3511.

Dolznig, H., Grebien, F., Sauer, T., Beug, H., and Müllner, E.W. 2004. Evidence for a size-sensing mechanism in animal cells. Nat. Cell Biol., 6: 899-905.

Edgar, B.A., Kiehle, C.P., and Schubiger, G. 1986. Cell cycle control by the nucleocytoplasmic ratio in early Drosophila development. Cell, $\mathbf{4 4}$ 365-372.

Ewen, M.E., Sluss, H.K., Sherr, C.J., Matsushime, H., Kato, J.Y., and Livingston, D.M. 1993. Functional interactions of the retinoblastoma protein with mammalian D-type cyclins. Cell, 73: 487-497.

Fox, M.H., Arndt-Jovin, D.J., Jovin, T.M., Baumann, P.H., and RobertNicoud, M. 1991. Spatial and temporal distribution of DNA replication sites localized by immunofluorescence and confocal microscopy in mouse fibroblasts. J. Cell Sci., 99: 247-253.

Giunta, M. and Pucillo, C. 1996. Techniques for monitoring cell cycle phases. In Cell Cycle-Materials and Methods (M. Pagano, ed.). Springer-Verlag Heidelberg, Germany, p.46-52.

Goda, T., Funakoshi, M., Suhara, H., Nishimoto, T., and Kobayashi, H. 2001. The N-terminal helix of Xenopus Cyclins A and B contributes to binding specificity of the Cyclin-CDK complex. J. Biol. Chem., 276: 15415-15422.

Ikeda, M.A., Jakoi, L., and Nevins, J.R. 1996. A unique role for the Rb protein in controlling E2F accumulation during cell growth and differentiation. Proc. Natl. Acad. Sci. USA, 93: 3215-3220.

Jeffrey, P.D., Tong, L., and Pavletich, N.P. 2000. Structural basis of inhibition of CDK-cyclin complexes by INK4 inhibitors. Genes Dev., 14: 3115-3125.

Kato, J., Matsushime, H., Hiebert, S.W., Ewen, M., and Sherr, C.J. 1993. Direct binding of cyclin $\mathrm{D}$ to the retinoblastoma gene product $(\mathrm{pRb})$ and $\mathrm{pRb}$ phosphorylation by the cyclin D dependent kinase CDK4. Genes Dev., 7: 331-342.

Kato, J.Y., Matsuoka, M., Strom, D.K., and Sherr, C.J. 1994. Regulation of cyclin D-dependent kinase 4 (cdk4) by cdk4-activating kinase. Mol. Cell. Biol., 14: 2713-2721.

LaBaer, J., Garrett, M.D., Stevenson, L.F., Slingerland, J.M., Sandhu, C., Chou, H.S., Fattaey, A., and Harlow, E. 1997. New functional activities for the p21 family of CDK inhibitors. Genes Dev., 11: 847-862.

Leblond, C.P. and El-Alfy, M. 1998. The eleven stages of the cell cycle, with emphasis on the changes in chromosomes and nucleoli during interphase and mitosis. Anat. Rec., 252: 426-443.

Lukas, J., Bartkova, J., and Bartek, J. 1996. Convergence of mitogenic signalling cascades from diverse classes of receptors at the cyclin Dcyclin-dependent kinase-pRb-controlled G1 checkpoint. Mol. Cell Biol., 16: 6917-6925.

Lundberg, A.S. and Weinberg, R.A. 1998. Functional inactivation of the retinoblastoma protein requires sequential modification by at least two distinct cyclin-CDK complexes. Mol. Cell Biol., 18: 753-761.

Makhnevych, T., Lusk, C.P., Anderson, A.M., Aitchison, J., and Wozniak, R.W. 2003. Cell cycle regulated transport controlled by alterations in the nuclear pore complex. Cell, 115: 813-823.

Masui, Y. and Wang, P. 1998. Cell cycle transition in early embryonic development of Xenopus laevis. Biol. Cell, 90: 537-548.

Mitchison, J.M. 1971. The biology of the cell cycle, Cambridge: Cambridge University Press, UK, p.128-158.

Mittnacht, S. and Weinberg, R.A. 1991. G1/S phosphorylation of the retinoblastoma protein is associated with an altered affinity for the nuclear compartment. Cell, 65: 381-393.

Moberg, K.M., Starz, A., and Lees, J.A. 1996. E2F-4 switches from p130 to 107 and pRB in response to cell cycle reentry. Mol. Cell. Biol., 16: 1436-1449.

Moore, J.D., Yang, J., Truant, R., and Kornbluth, S. 1999. Nuclear import of $\mathrm{Cdk} /$ cyclin complexes: identification of distinct mechanisms for import of Cdk2/cyclin E and Cdc2/cyclin B1. J. Cell Biol., 144: 213224.

Moore, M.S. and Blobel, G. 1992. The two steps of nuclear import, targeting to the nuclear envelope and translocation through the nuclear pore, require different cytosolic factors. Cell, 69: 939-950.

Morris, M.C., Gondeau, C., Tainer, J.A., and Divita, G. 2002. Kinetic mechanism of activation of the Cdk2/cyclin A complex, key role of the C-lobe of the CDK. J. Biol. Chem., 277: 23847-23853.

Müller, D., Thieke, K., Bürgin, A., Dickmanns, A., and Eilers, M. 2000. Cyclin E-mediated elimination of p27 requires its interaction with the nuclear pore-associated protein mNPAP60. EMBO J., 19: 2168-2180.

Nili, E., Cojocaru, G.S., Kalma, Y., Ginsberg, D., Copeland, N.G., Gilbert, D.J., Jenkins, N.A., Berger, R., Shaklai, S., Amariglio, N., Brok-Simoni, F., Simon, A.J., and Rechavi, G. 2001. Nuclear membrane protein LAP2 $\beta$ mediates transcriptional repression alone and together with its binding partner GCL (germ-cell-less). J. Cell Sci., 114: 3297-3307.

Pan, D., Estévez-Salmerón, L.D., Stroschein, S.L., Zhu, X., He, J., Zhou, S., and Luo, K. 2005. The integral inner nuclear membrane protein MAN1 physically interacts with the R-Smad proteins to repress signaling by the transforming growth factor- $\beta$ superfamily of cytokines. $J$. Biol. Chem., 280: 15992-16001.

Panté, N. and Aebi. U. 1996. Sequential binding of import ligands to distinct nucleopore regions during their nuclear import. Science, 273: $1729-1732$.

Perez-Roger, I., Kim, S.-H., Griffiths, B., Sewing, A., and Land, H. 1999. Cyclins D1 and D2 mediate Myc-induced proliferation via sequestration of $\mathrm{p} 27^{\mathrm{Kipl}}$ and $\mathrm{p} 21^{\mathrm{Cipl}}$. EMBO J., 18: 5310-5320.

Prescott, D.M. 1956. Relation between cell growth and cell division. II. The effect of cell size on cell growth rate and generation time in Amoeba proteus. III. Changes in nuclear volume and growth rate and prevention of cell division in Amoeba proteus resulting from cytoplasmic amputations. Exp. Cell Res., 11: 86-98.

Quelle, D.E., Ashmun, R.A., Shurteleff, S.A. Kato, J-Y., Bar-Sagi, D., Roussel, M.F., and Sherr, C.J. 1993. Overexpression of mouse D-type cyclins accelerates G1 phase in rodent fibroblasts. Genes Dev., 7: 15591571

Resnitzky, D., Gossen, M., Bujard, H., and Reed, S. 1994. Acceleration of the G1/S phase transition by expression of cyclins Dl and E with an inducible system. Mol. Cell Biol., 14: 1669-1679.

Rodgers, L. 1998. Flow cytometry. In: Cells: a laboratory manual (D.L. Spector, R.D. Goldman, and L.A. Leinwand, eds.). Cold Spring Harbor Laboratory Press, Cold Spring Harbor, New York, p.16.1-16.9.

Rout, M.P., Aitchison, J.D., Magnasco, M.O., and Chait, B.T. 2003. Virtual gating and nuclear transport: the hole picture. Trends Cell Biol., 13: 622-628.

Saitoh, H., Pizzi, M.D., and Wang, J. 2002. Perturbation of SUMOlation enzyme Ubc9 by distinct domain within nucleoporin RanBP2/Nup358. J. Biol. Chem., 277: 4755-4763.

Sherr, C.J. 1993. Mammalian G1 cyclins. Cell, 73: 1059-1065.

Sherr, C.J. and Roberts, J. M. 1999. CDK inhibitors: positive and negative regulators of G1-phase progression. Genes Dev., 13: 1501-1512.

Swanson, J.A., Lee, M., and Knapp, P.E. 1991. Cellular dimensions affecting the nucleocytoplasmic volume ratio. J. Cell Biol., 115: 941-948.

Szekely, L., Uzvolgyi, E., Jiang, W.Q., Durko, M., Wiman, K.G., Klein, G., and Sumegi, J. 1991. Subcellular localization of the retinoblastoma protein. Cell Growth Differ., 2: 287-295.

Weis, K. 2003. Regulating access to the genome: nucleocytoplasmic transport throughout the cell cycle. Cell, 112: 441-451.

Wells, N.J., Watanabe, N., Tokusumi, T., Jiang, W., Verdecia, M.A., and 
Hunter, T. 1999. The C-terminal domain of the Cdc2 inhibitory kinase Myt1 interacts with Cdc2complexes and is required for inhibition of G2/ M progression. J. Cell Sci., 112: 3361-3371.

Zagon, I.S., Verderame, M.F., and McLaughlin, P.J. 2002. The biology of the opioid growth factor receptor (OGFr). Brain Res. Rev., 38: 351-376.

Zetterberg, A. and Larsson, O. 1995. Cell cycle progression and cell growth in mammalian cells: kinetic aspects of transition events. In: Cell cycle control, eds. Hutchinson, C. and Glover, C.M. New York: Oxford University Press, 206-227.
Zhang, L., Zhou, H., Su, Y., Sun, Z., Zhang, H., Zhang, L., Zhang, Y., Ning, Y., Chen, Y.-G., and Meng, A. 2004. Zebrafish Dpr2 inhibits mesoderm induction by promoting degradation of Nodal receptors. Science, 306: 114-117.

Zhou, B.-B. and Elledge, S.J. 2000. The DNA damage response: putting checkpoints in perspective. Nature, 408: 433-439.

(Received for publication, May 13, 2008, accepted, July 15, 2008 and published online, October 1, 2008) 